\title{
Acrofrontofacionasal dysostosis
}

INSERM

\section{Source}

INSERM. (1999). Orphanet: an online rare disease and orphan drug data base.

Acrofrontofacionasal dysostosis. ORPHA:1784

Acro-fronto-facio-nasal dysostosis is a congenital malformation syndrome characterized by the association of facial and skeletal anomalies with severe intellectual deficit and occasional genitourinary anomalies. 